University of Wollongong

Research Online

Faculty of Engineering and Information

Faculty of Engineering and Information

Sciences - Papers: Part B

Sciences

2018

Investigation on the optimal cooling tower input capacity of a cooling tower assisted ground source heat pump system

Xuemei Gong

Zhejiang University, xgong@uow.edu.au

Lei Xia

University of Wollongong, Ix873@uowmail.edu.au

Zhenjun $\mathrm{Ma}$

University of Wollongong, zhenjun@uow.edu.au

Guangming Chen

Zhejiang University

Lili Wei

Ningbo University

Follow this and additional works at: https://ro.uow.edu.au/eispapers1

Part of the Engineering Commons, and the Science and Technology Studies Commons

Research Online is the open access institutional repository for the University of Wollongong. For further information contact the UOW Library: research-pubs@uow.edu.au 


\title{
Investigation on the optimal cooling tower input capacity of a cooling tower assisted ground source heat pump system
}

\author{
Abstract \\ Coupling auxiliary cooling devices with ground source heat pump (GSHP) systems in cooling dominated \\ areas can effectively solve the ground thermal imbalance problem. However, the input capacity of the \\ auxiliary heat rejecter directly affects the performance of such hybrid ground source heat pump (HGSHP) \\ systems. This paper presents an investigation on the optimal cooling tower input capacity of a cooling \\ tower assisted GSHP system through both experiments and simulations. The experiments were carried \\ out based on a HGSHP system implemented in an office building and the experimental results were used \\ to validate a numerical model. A simulation system of the cooling tower assisted GSHP system was then \\ developed using TRNSYS and validated against the experimental data collected. The impacts of the \\ cooling tower input capacity on the soil temperature and the system performance were simulated. The \\ results showed that the soil heat accumulation could be effectively alleviated when the cooling tower \\ input capacity ratio (CTICR) was greater than $50 \%$. The optimal cooling tower input capacity was highly \\ dependent on the operation scenario used. The optimal CTICR under two operation scenarios considered \\ was around $54 \%$, while that under the other operation scenarios was around $63 \%$. The control strategy \\ based on the fixed temperature difference between the cooling water leaving the heat pump and the \\ ambient air dry-bulb temperature was found to be the optimal control strategy for the system studied.

\section{Disciplines} \\ Engineering | Science and Technology Studies

\section{Publication Details} \\ Gong, X., Xia, L., Ma, Z., Chen, G. \& Wei, L. (2018). Investigation on the optimal cooling tower input \\ capacity of a cooling tower assisted ground source heat pump system. Energy and Buildings, 174 \\ 239-253.
}




\section{Investigation on the optimal cooling tower input capacity of a cooling tower assisted ground source heat pump system}

(1)

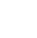

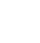

6

Abstract: Coupling auxiliary cooling devices with ground source heat pump (GSHP) systems in cooling dominated areas can effectively solve the ground thermal imbalance problem. However, the input capacity of the auxiliary heat rejecter directly affects the performance of such hybrid ground source heat pump (HGSHP) systems. This paper presents an investigation on the optimal cooling tower input capacity of a cooling tower assisted GSHP system through both experiments and simulations. The experiments were carried out based on a HGSHP system implemented in an office building and the experimental results were used to validate a numerical model. A simulation system of the cooling tower assisted GSHP system was then developed using TRNSYS and validated against the experimental data collected. The impacts of the cooling tower

8 input capacity on the soil temperature and the system performance were simulated. The results 9 showed that the soil heat accumulation could be effectively alleviated when the cooling tower input capacity ratio (CTICR) was greater than 50\%. The optimal cooling tower input capacity 1 was highly dependent on the operation scenario used. The optimal CTICR under two operation 22 scenarios considered was around 54\%, while that under the other operation scenarios was around $363 \%$. The control strategy based on the fixed temperature difference between the cooling water 
24 leaving the heat pump and the ambient air dry-bulb temperature was found to be the optimal

25 control strategy for the system studied.

26 Keywords: Hybrid ground source heat pump; Experiment; Simulation; Cooling tower; Input

27 capacity ratio; Control strategy.

28

29 Nomenclature

$30 \quad C \quad$ specific heat $(\mathrm{kJ} /(\mathrm{kg} \mathrm{K}))$

$31 \quad D \quad$ regression coefficient

32 f.s full scale

$33 \quad$ flow rate $(\mathrm{L} / \mathrm{s})$

$34 \quad$ gravity acceleration $\left(\mathrm{kg} \mathrm{m} / \mathrm{s}^{2}\right)$

$35 H \quad$ pump head (m)

$36 \quad$ Accumulated heat dissipation or heat quantity $(\mathrm{kJ})$

$37 \dot{Q} \quad$ heat dissipation rate $(\mathrm{kW})$

38 rdg reading

$39 \quad \mathrm{~T} \quad$ temperature $\left({ }^{\circ} \mathrm{C}\right)$

$40 \quad W \quad$ accumulated power consumption $(\mathrm{kWh})$

$41 \quad w \quad$ transient power consumption (W)

$42 \beta \quad$ correction coefficient

$43 \quad$ efficiency

$44 \rho \quad$ density $\left(\mathrm{kg} / \mathrm{m}^{3}\right)$

45

46 Subscripts

$47 \quad a \quad$ actual condition

48 aux auxiliary cooling system

$49 \quad b \quad$ borehole wall

$50 d$ daily

51 des design

$52 e \quad$ end

53 ET fixed entering temperature control strategy

$54 f \quad$ auxiliary heat dissipation

$55 g \quad$ ground heat exchanger

56 gi inlet water of the ground heat exchanger

57 go outlet water of the ground heat exchanger 


$\begin{array}{lll}58 & \text { HP } & \text { heat pump } \\ 59 & i & \text { initial } \\ 60 & \text { in } & \text { inlet } \\ 61 & p & \text { pump } \\ 62 & \text { RT } & \text { fixed running time control strategy } \\ 63 & r & \text { rated condition } \\ 64 & \text { s } & \text { seasonal } \\ 65 & \text { sha } & \text { soil heat accumulator } \\ 66 & \text { sou } & \text { soil outside the U-tube } \\ 67 & \text { source } & \text { source side } \\ 68 & \text { TD } & \text { fixed temperature difference control strategy } \\ 69 & \text { ti } & \text { inlet water of the water tank } \\ 70 & \text { to } & \text { outlet water of the water tank } \\ 71 & \text { user } & \text { user side }\end{array}$

73 Abbreviations

74 ACSEU energy use of auxiliary cooling system

75 ATRSHA daily average temperature rise of soil heat accumulator

76 ATRSHAS seasonal average temperature rise of soil heat accumulator

77 ATRSOU daily average temperature rise of soil outside the U-tube

78 ATRSOUS seasonal average temperature rise of soil outside the U-tube

79 COP coefficient of performance

80 CTICR cooling tower input capacity ratio

81 FET fixed entering temperature control strategy

82 FTD fixed temperature difference control strategy

83 FRT fixed running time control strategy

84 GHE ground heat exchanger

85 GSHP ground-source heat pump

86 HGSHP hybrid ground-source heat pump

87 PAHD percentage of daily auxiliary heat dissipation to total daily condensation load

88 SEU daily system energy use

89 SEUS seasonal system energy use

90 UEU daily energy use of heat pump unit

91 UEUS seasonal energy use of heat pump unit 


\section{Introduction}

Ground source heat pump (GSHP) as one of the most energy efficient and environmental-friendly air-conditioning technologies, has been receiving increasing attention since it has been developed [1-3]. One of the major challenges relating to the application of GSHP systems is the ground thermal imbalance, which can result in performance deterioration of

98 GSHP systems [4-6].

In order to solve this problem, hybrid ground source heat pump (HGSHP) systems, which

100 utilize auxiliary heat sink or source to supply a fraction of building cooling or heating demand,

101 have been studied [7-9]. The use of HGSHP systems can effectively alleviate ground thermal

102 imbalance, and in the meantime, can reduce the initial costs and ground area requirement in

103 comparison to conventional stand-alone GSHP systems [10, 11]. In cooling dominated areas,

104 where cooling demand is generally higher than heating demand, cooling tower is normally used 105 as the auxiliary heat rejecter in HGSHP systems. Fig. 1 illustrates two different types of cooling 106 tower assisted GSHP systems with serial configuration and parallel configuration.

107 The feasibility and effectiveness of cooling tower assisted GSHP systems have been 108 extensively studied. Man et al. [5, 12], for instance, investigated the performance of a cooling 109 tower assisted GSHP system in hot climate conditions through simulations. The simulation results

110 showed that this HGSHP system can effectively solve the heat accumulation problem and save

111 both initial cost and operating cost as compared to a conventional GSHP system. Hackel and

112 Pertzborn [13] analyzed the performance of three HGSHP systems including two cooling tower

113 assisted systems and one boiler assisted system by using both the operation data collected from

114 the real projects and simulation data. The results showed that appropriate use of HGSHP systems 
115 in buildings with unbalanced cooing and heating loads was more cost effective than that using the

116 stand-alone GSHP or conventional systems. Sayyadi and Nejatolahi [14] performed a

117 multi-objective optimization of a cooling tower assisted GSHP system, in which both

118 thermodynamic and thermoeconomic objectives were considered simultaneously. The major

119 design parameters of this HGSHP system were optimized using a genetic algorithm. Park et al.

120 [15] investigated the performance of a cooling tower assisted GSHP system with different

121 amounts of refrigerant charge, and different secondary fluid flow rates of the ground loop and the

122 supplemental loop, respectively. The optimal refrigerant charge and optimal secondary fluid flow

123 rates were identified through a number of experimental tests. The coefficient of performance

124 (COP) of this HGSHP system with optimal operating parameters was $21 \%$ higher than that of a

125 conventional GSHP system. Lee et al. [16] investigated the transient characteristics of a cooling

126 tower assisted GSHP system through experimental tests. The results showed that the performance

127 enhancement of this system was highly dependent on the leaving fluid temperature set-point of

128 the ground heat exchanger (GHE). The COP of this HGSHP system at the optimal set-point

129 temperature of $30{ }^{\circ} \mathrm{C}$ was $7.2 \%$ higher than that of a stand-alone GSHP system. Several studies

130 evaluated the performance of the cooling tower assisted GSHP systems with different flow loop

131 configurations. For instance, Park et al. [17] experimentally investigated the energy performance

132 of a cooling tower assisted GSHP system with both parallel and serial configurations, under

133 various leaving fluid temperatures of the GHE and flow rates in the supplemental loop,

134 respectively. The results showed that the COPs of the HGSHP with parallel and serial

135 configurations were $18 \%$ and $6 \%$, higher than that of a stand-alone GSHP system, respectively.

136 The HGSHP with parallel configuration rejected more heat into the supplemental plate heat 
137 exchanger than that with serial configuration at a lower flow rate in the supplemental loop. Lee et

138 al. [18] also analyzed the performance of a cooling tower assisted GSHP system with parallel and

139 serial configurations through experimental tests. The experimental results indicated that the

140 HGSHP system with serial configuration with up-stream flow showed a relatively higher COP

141 and a lower heat accumulation than that with the downstream flow. The COPs of the HGSHP

142 system with the serial and parallel configurations were $15 \%$ and $7 \%$ higher than that of a

143 stand-alone GSHP system, respectively. Zhou et al. [19] developed a simulation system for a

144 cooling tower assisted GSHP with parallel and serial configurations in TRNSYS. The 30 years

145 operation of the system under different operation schemes was simulated. The results showed that

146 activating the cooling tower during the transition seasons when the temperature difference

147 between the air wet-bulb temperature and the ground temperature was $8-12{ }^{\circ} \mathrm{C}$ offered the highest

148 benefits of using this HGSHP system. The system with the parallel configuration used less energy

149 in 30 years operation than that with the serial configuration. The results from the aforementioned

150 studies demonstrated that cooling tower assisted GSHP systems outperformed conventional

151 stand-alone GSHP systems in terms of energy use and ground thermal balance maintenance.

152 However, the operating parameters and control strategies used for such systems should be

153 carefully determined.

154 The energy performance of a cooling tower assisted GSHP system highly depends on the

155 control strategies used. The control strategies used for cooling tower assisted GSHP systems

156 could be broadly categorized into three groups: 1) to activate the cooling tower based on the

157 temperature set-point of the heat pump entering/existing fluid; 2) to activate the cooling tower

158 based on the temperature difference between the heat pump entering/exiting fluid temperature 

and the ambient air dry-bulb/wet-bulb temperature and; 3) to activate the cooling tower during a

160 fixed time period. The results from several studies [5, 20-22] suggested that the control strategies

161 that have longer operation hours of the cooling tower provided more benefits than those with less

162 operation hours, and the control strategy based on the difference between the heat pump exiting

163 fluid temperature and the air wet-bulb temperature outperformed the others. Yang et al. [23]

164 investigated three intermittent operation strategies for a HGSHP system with a double-cooling

165 tower to solve the problem of the underground heat accumulation. The three operation strategies

166 activated the cooling towers and the GHE at different time periods in a week. The simulation

167 results showed that the intermittent operation strategies investigated can significantly alleviate

168 soil heat accumulation. The optimal intermittent operating condition that favors both power

169 consumption reduction and soil temperature recovery was also identified through an economic

170 analysis. Fan et al. [24] purposed and analyzed four control strategies for cooling tower assisted

171 GSHP systems. The results showed that, the conrol strategy that combined the entering water

172 temperature control and wet-bulb temperature difference control has the lowest energy use, but

173 the soil temperature rise after 10 years of operation was slightly higher than $3^{\circ} \mathrm{C}$. The other three

174 strategies with the cooling tower running during the transition season can control the soil

175 temperature rise after 10 years of operation within $3^{\circ} \mathrm{C}$ but lose the benefit of lower energy use.

$176 \mathrm{Hu}$ et al. $[25,26]$ employed a control strategy using extremum seeking control to optimize the

177 operation of a cooling tower assisted GSHP system. The combined power consumption of the

178 GHE loop water pump, cooling tower fan and pump, and heat pump compressor was minimized

179 through optimizing the cooling tower fan speed and water pump speed. Cui et al. [27] analyzed

180 the performance of system configurations and control strategies of a cooling tower assisted GSHP 
181 system using TRNSYS. It was found that the optimal auxiliary cooling ratio for both parallel and 182 serial configurations of this HGSHP was 0.5 . The fixed load ratio control and the fixed entering 183 temperature control can provide a better performance for parallel and serial HGSHP systems, 184 respectively.

The majority of the existing studies on the control of cooling tower assisted GSHP systems

186 focused on the system performance comparison of using different control strategies or the control

187 of the system under a certain cooling tower input capacity. The system performance under varied

188 cooling tower input capacities and the relationship between the control strategy and the optimal

189 cooling tower input capacity have not been extensively studied.

190 In this study, the performance of a cooling tower assisted GSHP system with serial

191 configuration implemented in an office building was first evaluated. A simulation system was

192 then developed using TRNSYS and validated using the operation data collected from the

193 experiments. The system performance and the soil temperature variation under various cooling

194 tower input capacities and different operation scenarios were then studied through simulation

195 exercises. The optimal cooling tower input capacity under different system operation scenarios

196 for the system was then identified. The method used in this study can be used to guide and

197 facilitate the design and control of cooling towers in cooling tower assisted GSHP systems.

\section{2. Description of the experimental system}

200 The experimental system concerned was implemented in an office building in Ningbo University

201 of Technology, which is located in the hot summer and cold winter region of China. The system

202 was used to provide cooling and heating to the building with the design cooling and heating 
204 system are illustrated in Fig. 2 and Fig. 3, respectively. The system mainly consists of two 205 water-to-water heat pump units, two chilled water pumps (e.g. one for standby) and two cooling 206 water pumps (e.g. one for standby), ground heat exchangers (GHEs), an indoor air handling 207 system, an auxiliary cooling system, and a monitoring and control system. The specifications of 208 the major components are summarized in Table 1.

209 In this system, the cooling water at the source side of the HGSHP system is circulated among the 210 condenser of the heat pump, the auxiliary cooling system and the GHE loop, while the chilled 211 water at the load side is circulated between the evaporator of the heat pump and the indoor air

212 handling system. The ground heat exchanger (GHE) loop was sized based on the design heating

213 load and the measured soil properties using the design method presented in $[10,28]$. The

214 borehole field consists of 12 single U-tube heat exchanger boreholes with a depth of 75 meters

215 each. The layout of the borehole field is shown in Fig. 4 and the major design parameters of the

216 GHEs are summarized in Table 2. Fan coils were used for indoor air handling. The auxiliary

217 cooling system was sized based on the difference between the building design cooling and 218 heating loads using the peak algorithm method developed by Kavanaugh and Rafferty [29], 219 which is the recommended method to size the auxiliary cooling system of HGSHP systems in 220 Chinese standard [30]. The water tank in the auxiliary cooling system was used as a heat 221 exchanger between the auxiliary cold source and the cooling water circulation. The auxiliary cold 222 source used in the system is city water. The measuring points above the ground and underground 223 are shown in Fig. 2 and Fig. 4, respectively. The measuring points above the ground were used to 224 measure the water temperature, flow rates at different locations and power consumption, while 
The auxiliary cooling system was connected with the GHEs in series with the up-stream flow

229 configuration, in which the cooling water flows through the condenser, the auxiliary system and

230 the GHEs in series, since the system with the up-stream flow configuration can result in a better

231 energy performance than that with the down-stream flow configuration [18]. This experimental

232 system can operate with or without the auxiliary cooling system through ON/OFF control of three

233 isolation valves (valves V1-V3 in Fig. 2). When the system operates without the auxiliary cooling

234 system (i.e. by opening the valve V1 and closing the valves V2 and V3), the heat will be fully

235 rejected to the ground through the GHEs. When the system operates with the auxiliary cooling

236 system (by opening the valves V2 and V3 and closing the valve V1), a fraction of heat will be

237 dissipated through the auxiliary cooling system, which is controlled by changing the water side

238 flow rate of the auxiliary cooling system through regulating the valves V3 and V4.

\section{Modelling of the cooling tower assisted GSHP system}

241 A virtual simulation system of the cooling tower assisted GSHP system was developed based on

242 the experimental system using TRNSYS. In this virtual system, a cooling tower with the same

243 capacity as that of the auxiliary cooling system in the experimental system was used as the

244 auxiliary heat rejecter. The major design parameters of the cooling tower are listed in Table 4. A

245 plate heat exchanger was used between the cooling tower circulation and the cooling water

246 circulation instead of a water tank. The GSHP system was simplified with one heat pump unit 
247 with the same heating and cooling capacity as the sum of the two heat pump units used in the

248 experimental system. The other components used in this virtual system and their parameters were

249 the same as that used in the experimental system.

250 An illustration of the virtual simulation system is shown in Fig. 5. There are three major water

251 loops in this system, including the chilled water loop, the cooling water loop and the auxiliary

252 cooling loop. The major simulation models used to develop the simulation system are described

253 below.

\section{$254 \quad 3.1$ Water-to-water heat pump model}

255 The performance of the water-to-water heat pump was simulated using the model presented in

256 ASHRAE Handbook [31]. In this model, the instantaneous power consumption of the heat pump

257 is represented as a function of the chilled water inlet temperature and cooling water inlet 258 temperature of the heat pump, as expressed in Eq. (1).

$$
w_{H P, a}=w_{H P, r} \sum_{i=0}^{2} \sum_{j=0}^{2} D_{i j}\left(T_{u s e r, i n, r}-T_{u s e r, i n, r}\right)^{i}\left(T_{\text {source }, \text { in }, a}-T_{\text {source }, \text { in }, r}\right)^{j}
$$

260 where $w$ is the power consumption, $T$ is the temperature and $D_{i j}$ are the regression coefficients,

261 which were determined based on the performance data provided by the manufacturer, and the

262 values used are provided in Table 5. The subscripts HP, $a, r$, user and in represent heat pump,

263 actual condition, rated condition, user side and inlet, respectively.

\section{$264 \quad 3.2$ Ground heat exchanger model}

265 The duct storage (DST) system model proposed by Hellstrom [32] was used to simulate the

266 performance of vertical GHEs. This model was developed based on the finite line-source model

267 and has been successfully included in TRNSYS as a standard model (Type 557). The detailed 
modelling as one heat accumulator instead of simulation of each individual borehole.

\subsection{Cooling tower model}

271 Cooling tower is used as the auxiliary heat rejecter in this HGSHP system. The standard cooling

272 tower model (Type 51a) in the TRNSYS library was used to simulate the performance of the

273 counter flow cooling tower, in which the heat transfer process was simulated using $\varepsilon-$ NTU

274 method proposed by Jaber and Webb [33]. The schematic of the counter flow cooling tower used

275 in the system is shown in Fig. 7.

\section{$276 \quad 3.4$ Plate heat exchanger model}

277 In this study, the plate heat exchanger was used between the auxiliary cooling loop and the

278 cooling water loop. The simplified heat exchanger model with a constant heat transfer efficiency

279 of 0.8 between the primary and secondary side fluid was used in the simulation.

$280 \quad 3.5$ Water pump model

281 The chilled water pump and cooling water pump used in this HGSHP system are constant speed

282 water pumps and their power consumption was calculated by using Eq. (2).

$$
w_{p}=\frac{\rho g G_{a} H}{\eta_{p}}
$$

284 where, $\rho$ is the density of the working fluid, $g$ is the gravity acceleration, $G$ is the water flow

285 rate, $H$ is the pump head, $\eta$ is the efficiency, and the subscripts $a$ and $p$ represent actual 286 condition and pump, respectively.

287 The auxiliary loop circulation pump used was a variable speed pump, which was used to 288 control the cooling tower input capacity by varying the water side flow rate of the cooling tower. 
289 A flow rate control signal was used, which was set as the proportion of the desired water flow

290 rate to the design water flow rate of the cooling tower. This flow rate control signal associated

291 with a number of control logics and signals (i.e. operating time, temperature, temperature

292 difference, etc.) formed the control logic for the variable speed pump. For a certain simulation

293 scenario, this pump control logic was firstly determined, and it remained constant during the

294 simulation. The power consumption of the variable speed pump can be calculated using Eq. (8)

295 [34].

$$
w_{p}=\frac{\rho g G_{a}^{3} H_{r}}{\eta_{p} G_{r}^{2}}
$$

\section{Operation scenarios for cooling tower assisted GSHP systems}

There are three typical operation schedules of the building air-conditioning system in

300 different types of office buildings. The typical operation schedules for the research and higher

301 education institutions, normal office buildings and government office buildings and primary and 302 secondary schools are from $6: 00$ to $22: 00$, from $8: 00$ to $18: 00$, and from $8: 30$ to $17: 30$,

303 respectively. There are also three typical control strategies that are used to operate the cooling 304 tower assisted GSHP system and they are presented as follows [20, 35].

305 (1) Control strategy based on the fixed entering cooling water temperature (FET): the cooling tower is activated when the entering cooling water temperature of the heat pump unit exceeds a pre-determined temperature;

(2) Control strategy based on the fixed temperature difference (FTD): the cooling tower is activated when the difference between the cooling water leaving temperature of the heat pump unit and the dry-bulb (or wet-bulb) temperature of ambient air exceeds a certain 
value;

312 (3) Control strategy based on the fixed running time (FRT): the cooling tower is activated during a predetermined time period of a day.

314 In this study, nine operation scenarios with different operation schedules and control

315 strategies were considered. The daily and seasonal performance of this cooling tower assisted

316 GSHP system under these nine operation scenarios were investigated using the simulation system

317 developed. The daily performance investigation was carried out in a typical summer day, and the

318 seasonal performance investigation was carried out during the whole cooling season from $20^{\text {th }}$

319 June to $10^{\text {th }}$ September. The details of these operation scenarios are provided in Table 6, in which

320 the set-points of each control strategy were determined based on the building load characteristic,

321 local standards and relevant studies $[20,23,27,35]$. In the FET control strategy, the temperature

322 set-point was set at $32{ }^{\circ} \mathrm{C}$. In the FTD control strategy, the cooling tower was activated when the

323 difference between the leaving cooling water temperature of the heat pump unit and the wet-bulb

324 temperature of ambient air was larger than $2.0{ }^{\circ} \mathrm{C}$, and was deactivated when the temperature

325 difference was less than $1.5{ }^{\circ} \mathrm{C}$. In the FRT control strategy, the cooling tower was activated

326 during the whole operation period. The FET control and FTD control were realized by using a

327 temperature difference controller (Type 2) in TRNSYS and the FRT control strategy was simply

328 realized by setting the operation period of the GSHP system and the auxiliary cooling system.

\section{5. Results and discussion}

\section{$331 \quad 5.1$ Experimental tests}

332 The experimental tests were carried out in July and August in 2016. During the tests, the 
333 HGSHP system was operated based on the working hours and the cooling demand of the office

334 building. The system was generally operated from 8:30 to 17:30 in working days, but the

335 operation duration can be extended manually to adapt to the research requirement. The two heat

336 pump units were sequenced based on their design cooling capacities and the building load.

337 The variation in the measured daily borehole wall temperature, the calculated daily

338 accumulated heat dissipations of the GHEs and auxiliary cooling system, and the daily

339 accumulated system power consumption were used to validate the simulation system. The

340 average of all the measured underground temperatures was considered as the borehole wall

341 temperature. The daily accumulated heat dissipation of the GHEs and the auxiliary cooling

342 system were calculated using Eqs. (4) and (5), respectively, in which the transient heat exchanges

343 of the GHEs and the auxiliary cooling system were calculated by using Eqs. (6) and (7),

344 respectively. The daily accumulated power consumption was calculated using Eq. (8). The

345 percentage of the daily auxiliary heat dissipation to the total daily condensation load (PAHD) can

346 be determined using Eq. (9), based on the calculation results from Eqs. (4)-(7). The total daily

347 condensation load was the sum of the daily accumulated heat dissipation of the GHEs and the

348 auxiliary cooling system.

$$
\begin{array}{r}
Q_{g}=\sum_{i=1}^{n}\left(\dot{Q}_{g} \cdot \Delta t_{i}\right) \\
Q_{\text {aux }}=\sum_{i=1}^{n}\left(\dot{Q}_{\text {aux }} \cdot \Delta t_{i}\right)
\end{array}
$$




$$
P A H D=\frac{Q_{a u x}}{Q_{g}+Q_{a u x}} \times 100 \%
$$

355 where, $Q$ is the daily accumulated heat dissipation, $\dot{Q}$ is the transient heat dissipation, $\Delta t_{i}$ is

356 the measuring time interval, $n$ is the total number of measuring time intervals in a day, $G$ is the

357 water flow rate, $C$ is the specific heat capacity of the working fluid, $W$ is the daily accumulated

358 power consumption, and the subscripts $g, a u x, c, g i, g o$, ti and to represent GHE, auxiliary

359 cooling system, cooling water, inlet water of the GHE, outlet water of the GHE, inlet water of the

360 water tank and outlet water of the water tank, respectively.

\section{$361 \quad 5.2$ Model validation result}

362 The simulation model of the cooling tower assisted GSHP system was validated using the

363 system performance data collected from the experimental tests in two typical summer days (i.e.

$36428^{\text {th }}$ July and $13^{\text {th }}$ August) in 2016. In order to get enough performance data for model validation,

365 the system operation duration on $28^{\text {th }}$ July was extended manually from 7:42 to 19:02, during

366 which the system operated without the auxiliary cooling system. The system operation duration

367 on $13^{\text {th }}$ August was from 8:44 to $18: 00$, during which the system operated with the auxiliary

368 cooling system. The system operation duration, the PAHD, the initial borehole wall temperature

369 and the system control strategy used in the simulation were the same as those of the experimental

370 system. The validation results when the system operated with and without auxiliary cooling

371 system are presented in Fig. 8 and Fig. 9, respectively. It can be observed that the accumulated

372 heat pump and system power consumption, the borehole wall temperature $\left(T_{b}\right)$ and the

373 instantaneous COPs of the heat pump and the system obtained from the simulation agreed well

374 with those determined based on the experimental data during the majority of the operation period 
in both two days. The simulated $T_{b}$ normally decreased a little bit at the beginning of the simulation mainly due to the characteristic of the DST model and the iterative algorithm used in the model to calculate the soil temperature, and it was then gradually increased.

The simulated and measured borehole wall temperatures, the daily average borehole wall temperatures during the system operation, the daily accumulated power consumption of the heat pump unit and the whole system as well as the daily average COPs of the heat pump unit and the

381 whole system when the system operated with or without auxiliary cooling system were summarized in Table 7. It can be seen that the daily soil temperature variation, the daily accumulated power consumption and the daily average COPs obtained from the simulation agreed well with those obtained from the experimental tests. The highest relative error between the simulation and the experiments was less than $3.4 \%$, indicating the effectiveness of the system simulation model used. It is worthwhile to note that, the system operated with the auxiliary cooling system achieved a higher daily average COP of the whole system and a lower temperature rise in the borehole wall, in comparison to the system operated without the auxiliary cooling system.

\subsection{Auxiliary heat dissipation of the cooling tower under different operation scenarios}

Fig. 10 presents the relationship between the PAHD and the cooling tower input capacity ratio

392 (CTICR) under different system operation scenarios in the typical summer day. CTICR was defined as the ratio of the cooling tower input capacity to the maximum capacity of the cooling

394 tower. The cooling tower input capacity referred to the cooling tower capacity under the actual water flow rate in the auxiliary cooling loop, while the maximum capacity of the cooling tower 
loop. Therefore, CTICR can be expressed in Eq. (10).

$$
\mathrm{CTICR}=\beta \frac{G_{a u x, a}}{G_{a u x, d e s}}
$$

399 where, $\beta$ is the correction coefficient determined based on the performance data provided by

400 the manufacturer, and the subscripts aux and des reparent auxiliary cooling system and design,

401 respectively.

402 It can be seen that, under the FTD control and FRT control, the PAHD increased with the

403 increase of the CTICR, but the increasing rate was gradually decreased. The highest PAHD of

$40460 \%$ was achieved when the CTICR reached 100\%. Under the FET control, the PAHD increased

405 with the increase of the CTICR when CTICR was less than $54 \%$, but it decreased when further

406 increasing CTICR. This is mainly because, under the FET control, the cooling tower was only

407 activated when the entering cooling water temperature of the heat pump unit exceeded $32{ }^{\circ} \mathrm{C}$.

408 Increasing CTICR boosted the heat dissipation capacity of the cooling tower but reduced the

409 operation duration of the cooling tower. Further increasing CTICR resulted in a decrease in the

410 total auxiliary heat dissipation. The relationship between PAHD and CTICR revealed that

411 increasing the cooling tower input capacity did not result in an equivalent increase in the

412 auxiliary heat dissipation. The optimal CTICR should be determined based on the actual

413 operation condition and the control strategy used.

\subsection{Influence of the cooling tower input capacity on the soil temperature}

415 Under the cooling working condition, the heat rejection to the ground will increase the ground

416 temperature around the GHEs. The rise in the ground temperature will gradually deteriorate the

417 cooling performance of GSHP systems. The main purpose of using the auxiliary cooling system 
418 in a GSHP system is to achieve annual ground thermal balance, preventing performance

419 deterioration. Therefore, the influence of the cooling tower input capacity on the soil temperature 420 was investigated.

421 In this study, the performance of the 12 boreholes were assumed to be identical, since they

422 were used simultaneously during the system operation with the same inlet water temperature and

423 fluid flow rate. The average temperature of the soil heat accumulator and the average soil

424 temperature outside the U-tube were simulated using the DST model.

Fig. 11 presents the average temperature rise of the soil heat accumulator (ATRSHA) and the 426 average temperature rise of the soil outside the U-tube (ATRSOU) at the end of different 427 operation hours, and they were determined using Eq. (11) and Eq. (12), respectively.

$$
\begin{aligned}
& \text { ATRSHA }=\left(T_{\text {sha }, d, i}-T_{\text {sha }, d, e}\right) \\
& \text { ATRSOU }=\left(T_{\text {sou }, d, i}-T_{\text {sou }, d, e}\right)
\end{aligned}
$$

430 where, the subscripts sha, sou, $d$, $i$ and $e$ represent soil heat accumulator, soil outside the U-tube,

431 daily, initial and end, respectively.

It can be observed that the use of cooling tower was able to alleviate the soil heat 433 accumulation. Both ATRSHA and ATRSOU reduced significantly with the increase of CTICR 434 when it was less than $50 \%$, while this reduction became less significant when further increasing 435 CTICR. ATRSHA and ATRSOU can be reduced up to $0.5{ }^{\circ} \mathrm{C}$ and $3.2{ }^{\circ} \mathrm{C}$ respectively when the 436 capacity of the cooling tower was fully used (i.e. 100\% CTICR). It can also be seen that the FRT 437 control was the most effective strategy to alleviate the soil heat accumulation, followed by the 438 FTD control, and the FET control.

439 Fig. 12 presents the seasonal average temperature rise of the soil heat accumulator 
440 (ATRSHAS) and the seasonal average temperature rise of the soil outside the U-tube (ATRSOUS)

441 after the whole cooling season under different operation scenarios, and they were calculated using 442 Eq. (13) and Eq. (14), respectively.

$$
\begin{aligned}
& \text { ATRSHAS }=\left(T_{\text {sha }, s, i}-T_{\text {sha }, s, e}\right) \\
& \text { ATRSOUS }=\left(T_{\text {sou }, s, i}-T_{\text {sou }, s, e}\right)
\end{aligned}
$$

445 where, the subscripts $s$ represents seasonal.

It can be observed that the curves of ATRSHAS and ATRSOUS shared the similar variation

447 trend as those of ATRSHA and ATRSOU, respectively. Both ATRSHAS and ATRSOUS can be

448 reduced significantly when the cooling tower was used. The ATRSHAS under all operation

449 scenarios was less than $2.0{ }^{\circ} \mathrm{C}$ when the CTICR was greater than $50 \%$, which was the acceptable

450 temperature rise after the cooling season operation based on the annual simulation results.

The above results indicated that the input cooling tower capacity in the HGSHP system

452 should not be less than $50 \%$ of its maximum cooing capacity during the operation in order to

453 effectively alleviate the soil heat accumulation and maintain the ground thermal balance.

\subsection{Influence of the cooling tower input capacity on the system energy use}

Fig. 13 shows the daily system energy use (SEU) and the daily heat pump unit energy use

456 (UEU) with various CTICRs and under different system operation scenarios. It can be observed 457 that both SEU and UEU were closely related to the CTICR. With the increase of the CTICR, the 458 differences in SEU and UEU among the three control strategies became more significant under 459 all operation schedules.

460 Under the FRT control and FTD control, UEU always decreased with the increase of CTICR, 461 and the UEU under the FRT control was slightly lower than that under the FTD control. The UEU 
under the FET control was higher than that under the other control strategies, especially when the

463 CTICR was greater than 50\%. Since the actual auxiliary heat dissipation under the FET control 464 was significantly lower than that under the other two control strategies (See Fig. 10), the heat 465 pump unit under the FET control therefore provided more cooling energy, resulting in an increase 466 in the UEU.

467 From Fig. 13, it can also be observed that the CTICR that led to the minimization of SEU was 468 around $63 \%$ under all operation scenarios, except for the operation scenario FET8 which was 469 around 44\%. Under all operation schedules, the SEU under the FTD control was generally the 470 lowest, and those under the FRT control and FTD control were relatively close to each other.

471 The daily energy use of the auxiliary cooling system (ACSEU) was related to the CTICR and 472 the operation duration of the cooling tower. The relationship between ACSEU and CTICR under 473 the three operation schedules is shown in Fig. 14. It can be observed that the ACSEU under the 474 FTD control was generally lower than that under the FRT control but was higher than that under 475 the FET control.

476 From the above analysis, it can be concluded that under the FRT control, the operating time of 477 the cooling tower was the longest, which resulted in the highest ACSEU and the lowest UEU. 478 However, under the FET control, the operating time of the cooling tower was the lowest, with the 479 lowest ACSEU and the highest UEU. The daily system energy use under both two control 480 strategies were nearly the same. The system under the FTD control consumed the lowest amount 481 of energy in the typical summer day.

482 Fig. 15 shows the seasonal system energy use (SEUS) and the seasonal heat pump unit energy use (UEUS) with the variation of the CTICR under different system operation scenarios. It can be 
observed that UEUS decreased with the increase of the CTICR under all operation scenarios.

485 However, the decreasing rate was gradually reduced. Similar to the variation of SEU, there 486 existed an optimal CTICR that minimized the SEUS. This optimal CTICR was around 54\% under 487 the operation scenarios FTD16 and FRT16, and was around 63\% under the other operation 488 scenarios. The CTICR that minimized the SEUS under all operation scenarios was greater than $48950 \%$, which demonstrated that using the optimal CTICR identified could effectively alleviate the 490 soil heat accumulation and minimize the energy use of this HGSHP system. The corresponding 491 cooling tower input capacity under each operation scenario was therefore considered as the 492 optimal cooling tower input capacity. It is worthwhile to note that the optimal cooling tower input 493 capacities identified under all operation scenarios were always less than the maximum capacity of 494 the cooling tower, indicating that the cooling tower determined using the peak algorithm method 495 was oversized. The cooling tower for this HGSHP system could be re-sized based on the optimal 496 cooling tower input capacity identified in this section.

497 It can also be observed that the SEUS under the FET control was always the highest among 498 the three control strategies. The SEUS under the FRT control was slightly higher than that under 499 the FTD control under all operation scenarios. The FTD control was therefore considered as the 500 optimal control strategy among the three control strategies for this cooling tower assisted GSHP 501 system. It is worthwhile to note that these results were highly dependent on the climate condition, 502 and the optimal input cooling tower capacity and the optimal control strategy could be different 503 under different climate conditions. 


\section{Conclusion}

In this paper, the optimal cooling tower input capacity of a cooling tower assisted ground

507 source heat pump (GSHP) system was investigated based on experiments and simulations. An

508 experimental system of a hybrid GSHP (HGSHP) system with serial configuration was first

509 developed and implemented in a real engineering condition in the hot summer and cold winter

510 region of China. A simulation model of the cooling tower assisted GSHP system was then

511 developed based on this experimental system using TRNSYS and was validated using the

512 operation data collected from the experimental system. The system performance and soil

513 temperature variation under different cooling tower capacity ratios (CTICRs) and different

514 operation scenarios was investigated through simulation exercises. The model validation results

515 showed that, the majority of the operating parameters obtained from the simulation agreed well

516 with those determined from the experimental tests. The simulation results showed that the soil

517 heat accumulation could be effectively alleviated when the CTICR was greater than $50 \%$. The

518 optimal cooling tower input capacity was highly dependent on the system operation scenario used.

519 The longest operating time of the cooling tower was required under the fixed running time (FRT)

520 control and the lowest operating time of the cooling tower was required under the fixed entering

521 cooling water temperature (FET) control. The system energy use under the two control strategies

522 were nearly the same, both higher than that under the fixed temperature difference (FTD) control.

523 The optimal CTICR was around 54\% under the operation scenarios that operated the system from

524 6:00 to 22:00 under the FRT control, and operated the system from 6:00 to 22:00 under the FTD

525 control, while that under other operation scenarios was around $63 \%$. The optimal control strategy

526 identified was the FTD control, under which the system consumed the least amount of energy 
527 throughout the whole cooling season. The method used in this study can be used to guide and 528 facilitate the optimal design and control of cooling towers in cooling tower assisted GSHP 529 systems.

\section{$531 \quad$ References}

532 [1] L. Pu, D. Qi, K. Li, H. Tan, Y. Li, Simulation study on the thermal performance of vertical

533 U-tube heat exchangers for ground source heat pump system, Applied Thermal Engineering, 79 534 (2015) 202-213.

535 [2] Z. Wang, F. Wang, J. Liu, Z. Ma, E. Han, M. Song, Field test and numerical investigation on 536 the heat transfer characteristics and optimal design of the heat exchangers of a deep borehole 537 ground source heat pump system, Energy Conversion and Management, 153 (2017) 603-615.

538 [3] S. Huang, Z. Ma, P. Cooper, Optimal design of vertical ground heat exchangers by using 539 entropy generation minimization method and genetic algorithms, Energy Conversion and $540 \quad$ Management, 87 (2014) 128-137.

541 [4] Y. Yu, Z. Ma, X. Li, A new integrated system with cooling storage in soil and ground-coupled 542 heat pump, Applied Thermal Engineering, 28 (11-12) (2008) 1450-1462.

543 [5] Y. Man, H. Yang, J. Wang, Study on hybrid ground-coupled heat pump system for 544 air-conditioning in hot-weather areas like Hong Kong, Applied Energy, 87 (9) (2010) 2826-2833.

545 [6] Z. Wang, F. Wang, Z. Ma, X. Wang, X. Wu, Research of heat and moisture transfer influence 546 on the characteristics of the ground heat pump exchangers in unsaturated soil, Energy and 547 Buildings, 130 (2016) 140-149.

548 [7] G. Phetteplace, W. Sullivan, Performance of a hybrid ground-coupled pump system, ASHRAE 
transactions, 104 (1998) 763.

550 [8] A.D. Chiasson, C. Yavuzturk, Assessment of the viability of hybrid geothermal heat pump

551 systems with solar thermal collectors, ASHRAE transactions, 109 (2) (2003) 487-500.

552 [9] Y. Man, H. Yang, J.D. Spitler, Z. Fang, Feasibility study on novel hybrid ground coupled heat

553 pump system with nocturnal cooling radiator for cooling load dominated buildings, Applied

554 Energy, 88 (11) (2011) 4160-4171.

555 [10] ASHRAE, Commercial/institutional ground-source heat pump engineering manual, 556 ASHRAE, Inc., Atlanta, 1995.

557 [11] Z.S. Qi, Q. Gao, Y. Liu, Y.Y. Yan, J.D. Spitler, Status and development of hybrid energy

558 systems from hybrid ground source heat pump in China and other countries, Renewable and 559 Sustainable Energy Reviews, 29 (2014) 37-51.

560 [12] M. Yi, Y. Hongxing, F. Zhaohong, Study on hybrid ground-coupled heat pump systems,

561 Energy and Buildings, 40 (11) (2008) 2028-2036.

562 [13] S. Hackel, A. Pertzborn, Effective design and operation of hybrid ground-source heat pumps:

563 three case studies, Energy and Buildings, 43 (12) (2011) 3497-3504.

564 [14] H. Sayyadi, M. Nejatolahi, Thermodynamic and thermoeconomic optimization of a cooling

565 tower-assisted ground source heat pump, Geothermics, 40 (3) (2011) 221-232.

566 [15] H. Park, J.S. Lee, W. Kim, Y. Kim, Performance optimization of a hybrid ground source heat 567 pump with the parallel configuration of a ground heat exchanger and a supplemental heat rejecter 568 in the cooling mode, International Journal of Refrigeration, 35 (6) (2012) 1537-1546.

569 [16] J.S. Lee, H. Park, Y. Kim, Transient performance characteristics of a hybrid ground-source 570 heat pump in the cooling mode, Applied Energy, 123 (2014) 121-128. 
571 [17] H. Park, J.S. Lee, W. Kim, Y. Kim, The cooling seasonal performance factor of a hybrid 572 ground-source heat pump with parallel and serial configurations, Applied Energy, 102 (2013) $573 \quad 877-884$.

574 [18] J.S. Lee, K.S. Song, J.H. Ahn, Y. Kim, Comparison on the transient cooling performances of 575 hybrid ground-source heat pumps with various flow loop configurations, Energy, 82 (2015) $576 \quad 678-685$.

577 [19] S. Zhou, W. Cui, Z. Li, X. Liu, Feasibility study on two schemes for alleviating the 578 underground heat accumulation of the ground source heat pump, Sustainable Cities and Society, $57924(2016) 1-9$.

580 [20] C. Yavuzturk, J.D. Spitler, Comparative study of operating and control strategies for hybrid 581 ground-source heat pump systems using a short time step simulation model, ASHRAE 582 transactions, $106(2000)$ 192-209.

583 [21] Q. Zhang, N. Lv, S. Chen, H. Shi, Z. Chen, Study on operating and control strategies for 584 hybrid ground source heat pump system, Procedia Engineering, 121 (2015) 1894-1901.

585 [22] Z. Sagia, C. Rakopoulos, New control strategy for a hybrid ground source heat pump system 586 coupled to a closed circuit cooling tower, Journal of Applied Mechanical Engineering, 1 (2) 587 (2012) 1-8.

588 [23] J. Yang, L. Xu, P. Hu, N. Zhu, X. Chen, Study on intermittent operation strategies of a hybrid 589 ground-source heat pump system with double-cooling towers for hotel buildings, Energy and $590 \quad$ Buildings, $76(2014)$ 506-512.

591 [24] R. Fan, Y. Gao, L. Hua, X. Deng, J. Shi, Thermal performance and operation strategy optimization for a practical hybrid ground-source heat-pump system, Energy and Buildings, 78 
[25] B. Hu, Y. Li, B. Mu, S. Wang, J.E. Seem, F. Cao, Extremum seeking control of hybrid ground source heat pump system, International Refrigeration and Air Conditioning Conference,

5962014.

597 [26] B. Hu, Y. Li, B. Mu, S. Wang, J.E. Seem, F. Cao, Extremum seeking control for efficient 598 operation of hybrid ground source heat pump system, Renewable Energy, 86 (2016) 332-346.

599 [27] W. Cui, S. Zhou, X. Liu, Optimization of design and operation parameters for hybrid 600 ground-source heat pump assisted with cooling tower, Energy and Buildings, 99 (2015) 253-262.

601 [28] Standard China, Technical Guidelines for Building Application of Ground Source Heat 602 Pump System in Ningbo (S10-2010), Ministry of Housing, Urban and Rural Development of 603 China, China, 2010.

604 [29] S.P. Kavanaugh, K.D. Rafferty, Ground-source heat pumps: design of geothermal systems 605 for commercial and institutional buildings, American Society of Heating, Refrigerating and 606 Air-Conditioning Engineers, 1997.

607 [30] Standard China, Technical code for ground-source heat pump system (GB50366-2009),

608 Ministry of Housing, Urban and Rural Development of China, China, 2009.

609 [31] Systems and equipment, American Society of Heating, Refrigerating, and Air Conditioning 610 Engineers, Atlanta, GA, 1992.

611 [32] G. Hellström, Ground heat storage: thermal analyses of duct storage systems, Department of 612 Mathematical Physics, Lund University, Sweden, 1991.

613 [33] H. Jaber, R. Webb, Design of cooling towers by the effectiveness-NTU method, Journal of 614 Heat Transfer, 111 (4) (1989) 837-843. 
615 [34] S. Yang, H. Li, J. Yin, Development and application of variable frequency pump module 616 based on TRNSYS, Journal of HV\&AC, 8 (2015) 36-41.

617 [35] Y. Ma, Analysis on control strategy in compound gound-source heat pump system of the 618 office building of the typical climate zone, Master's thesis, Chongqing University, 2012.

619 
Table 1 Specifications of the major components used in the experimental system

\begin{tabular}{|c|c|c|}
\hline Component & Number & Parameter \\
\hline Heat pump unit 1\# & 1 & $\begin{array}{l}\text { Rated cooling capacity: } 24 \mathrm{~kW} ; \\
\text { Cooling power consumption: } 7.3 \mathrm{~kW} \text {; } \\
\text { Rated heating capacity: } 26 \mathrm{~kW} ; \\
\text { Heating power consumption: } 8.6 \mathrm{~kW} \text {. }\end{array}$ \\
\hline Heat pump unit 2\# & 1 & $\begin{array}{l}\text { Rated cooling capacity: } 18.5 \mathrm{~kW} \text {; } \\
\text { Cooling power consumption: } 3.9 \mathrm{~kW} \text {; } \\
\text { Rated heating capacity: } 20.5 \mathrm{~kW} \\
\text { Heating power consumption: } 5.4 \mathrm{~kW} \text {. }\end{array}$ \\
\hline Load side water pump & 2 & Rated power: $2 \mathrm{~kW}$; Rated flow rate: $4.5 \mathrm{~m}^{3} / \mathrm{h}$. \\
\hline Hot water tank & 1 & Volume: $200 \mathrm{~L}$ \\
\hline Source side water pump & 2 & Rated power: $2 \mathrm{~kW}$; Rated flow rate: $5.5 \mathrm{~m}^{3} / \mathrm{h}$. \\
\hline Indoor fan coil & 9 & $\begin{array}{l}\text { Rated cooling capacity: } 6.2 \mathrm{~kW} \text {; } \\
\text { Air side flow rate: } 1360 \mathrm{~m}^{3} / \mathrm{h} \text {. }\end{array}$ \\
\hline
\end{tabular}

Table 2 Design parameters of the GHEs

\begin{tabular}{ll}
\hline Parameters & Value \\
\hline Soil thermal conductivity $(\mathrm{W} / \mathrm{m} \cdot \mathrm{K})$ & 1.52 \\
Soil thermal diffusivity $\left(\mathrm{m}^{2} / \mathrm{s}\right)$ & 0.568 \\
Initial soil temperature $\left({ }^{\circ} \mathrm{C}\right)$ & 23.1 \\
Borehole depth $(\mathrm{m})$ & 75 \\
Number of borehole & 12 \\
Borehole distance $(\mathrm{m})$ & 4 \\
Borehole radius $(\mathrm{m})$ & 0.055 \\
U-tube outer radius $(\mathrm{m})$ & 0.0125 \\
U-tube thermal conductivity $(\mathrm{W} / \mathrm{m} . \mathrm{K})$ & 0.42 \\
\hline
\end{tabular}

Table 3 Details of the major measuring equipment

\begin{tabular}{|c|c|c|c|}
\hline Name & Measuring parameter & Test range & $\begin{array}{l}\text { Accuracy and } \\
\text { uncertainty }\end{array}$ \\
\hline $\begin{array}{l}\text { T type } \\
\text { thermocounle }\end{array}$ & Ambient air temperature & $-30 \sim 60$ & \pm 0.5 \\
\hline $\begin{array}{l}\text { Water proof } \\
\text { temperature } \\
\text { sensor }\end{array}$ & $\begin{array}{l}\text { Heat pump supply and return chilled } \\
\text { water temperatures; User side supply } \\
\text { and return water temperatures; } \\
\text { Cooling water temperatures before } \\
\text { and after heat pump units, auxiliary } \\
\text { cooling system and GHEs }\end{array}$ & $-50 \sim+100$ & \pm 0.1 \\
\hline $\begin{array}{l}\text { PT } 100 \text { water } \\
\text { proof temperature } \\
\text { sensor }\end{array}$ & $\begin{array}{l}\text { Borehole wall temperature at different } \\
\text { depths. }\end{array}$ & $-50 \sim+100$ & \pm 0.01 \\
\hline Flow meter & $\begin{array}{l}\text { Flow rates of chilled water and } \\
\text { cooling water }\end{array}$ & $\begin{array}{c}0 \sim 120 \\
0.028 \sim 205258 \\
\mathrm{~m}^{3} / \mathrm{h}\end{array}$ & $\begin{array}{l} \pm 0.2 \% \text { f.s or } \\
\pm 1 \% \text { rdg }\end{array}$ \\
\hline Power meter & Power consumption of heat pump & $0 \sim 15 \mathrm{~kW}$ & $\pm 0.1 \% \mathrm{rdg}$ \\
\hline
\end{tabular}


626

627 Table 4 Major design parameters of the cooling tower in the virtual HGSHP system

\begin{tabular}{cccccccc}
\hline $\begin{array}{c}\text { Rated cooling Water side Air side } \\
\text { capacity } \\
(\mathrm{kW})\end{array}$ & $\begin{array}{c}\text { Fan } \\
\text { flow rate } \\
\left(\mathrm{m}^{3} / \mathrm{h}\right)\end{array}$ & $\begin{array}{c}\text { Fan } \\
\left(\mathrm{m}^{3} / \mathrm{h}\right)\end{array}$ & $\begin{array}{c}\text { Tower } \\
(\mathrm{kW})\end{array}$ & $\begin{array}{c}\text { Toweter } \\
(\mathrm{mm})\end{array}$ & $\begin{array}{c}\text { Sump } \\
(\mathrm{mm})\end{array}$ & $\begin{array}{c}\text { Sump } \\
(\mathrm{mm})\end{array}$ & $\begin{array}{c}\text { Sigmeter } \\
(\mathrm{mm})\end{array}$ \\
\hline 26.0 & 8 & 4200 & 0.18 & 550 & 1460 & 420 & 930 \\
\hline
\end{tabular}

628

629

Table 5 Regression coefficients of the water-to-water heat pump model

\begin{tabular}{cccc}
\hline$D_{i j}$ & $i=0$ & $i=1$ & $i=2$ \\
\hline$j=0$ & 1.005 & 0.012 & 0.037 \\
$j=1$ & 0.281 & -0.056 & 0.053 \\
$j=2$ & 0.056 & 0.031 & -0.037 \\
\hline
\end{tabular}

630

631

Table 6 System operation scenarios considered in this study

\begin{tabular}{cccc}
\hline Scenario & Abbreviation & Control strategy & Operation schedule \\
\hline 1 & FET16 & FET control & 6:00-22:00 \\
2 & FTD16 & FTD control & (16 hours operation) \\
3 & FRT16 & FRT control & \\
4 & FET9 & FET control & $8: 00-17: 00$ \\
5 & FTD9 & FTD control & (9 hours operation) \\
6 & FRT9 & FRT control & \\
7 & FET8 & FET control & $8: 30-16: 30$ \\
8 & FTD8 & FTD control & (8 hours operation) \\
9 & FRT8 & FRT control & \\
\hline
\end{tabular}

632

633 Table 7 Comparison of major operation parameters between the experiment and the simulation

\begin{tabular}{|c|c|c|c|c|c|c|c|c|}
\hline \multirow[b]{2}{*}{ Parameter } & \multicolumn{4}{|c|}{ Without auxiliary cooling system } & \multicolumn{4}{|c|}{ With auxiliary cooling system } \\
\hline & Experiment & Simulation & $\begin{array}{l}\text { Relative } \\
\text { error }\end{array}$ & $\begin{array}{c}\text { Experimental } \\
\text { uncertainty }\end{array}$ & Experiment & Simulation & $\begin{array}{l}\text { Relative } \\
\text { error }\end{array}$ & $\begin{array}{c}\text { Experimental } \\
\text { uncertainty }\end{array}$ \\
\hline Operation duration & $7: 42-19: 02$ & $7: 42-19: 02$ & $0.00 \%$ & $0.00 \%$ & $8: 44-17: 54$ & $8: 44-17: 54$ & $0.00 \%$ & $0.00 \%$ \\
\hline PAHD & 0 & 0 & - & - & $9.10 \%$ & $9.10 \%$ & $0.10 \%$ & $\pm 5.4 \%$ \\
\hline $\begin{array}{l}\text { Initial borehole wall } \\
\text { temperature }\left({ }^{\circ} \mathrm{C}\right)\end{array}$ & 24.0 & 24.0 & $0.00 \%$ & $\pm 0.5 \%$ & 23.5 & 23.5 & $0.00 \%$ & $\pm 0.5 \%$ \\
\hline $\begin{array}{l}\text { Borehole wall } \\
\text { temperature after the } \\
\text { system operation }\left({ }^{\circ} \mathrm{C}\right)\end{array}$ & 27.2 & 27.2 & $-0.30 \%$ & $\pm 0.54 \%$ & 26.0 & 26.2 & $0.60 \%$ & $\pm 0.54 \%$ \\
\hline $\begin{array}{l}\text { Daily average borehole } \\
\text { wall temperature }\left({ }^{\circ} \mathrm{C}\right)\end{array}$ & 26.5 & 26.1 & $-1.20 \%$ & $\pm 0.54 \%$ & 25.3 & 25.3 & $-0.02 \%$ & $\pm 0.54 \%$ \\
\hline
\end{tabular}


Power consumption of the heat pump unit $(\mathrm{kWh})$

Power consumption of the whole system (kWh)

Daily average COP of heat pump unit

Daily average COP of the system
68.3

102.4

4.62

2.88
$67.9 \quad-0.60 \% \quad \pm 1.1 \%$

41.1

68.1

5.28

3.29

$-1.7 \% \quad \pm 5.1 \%$

$41.5 \quad 1.00 \%$

$\pm 1.1 \%$

634 


\section{Figure Captions}

637 Fig. 1 Schematic of the cooling tower assisted GSHP systems

638 Fig. 2 Schematic of the experimental system and the measurement points above the ground

639 Fig. 3 Outlook of the experimental system

640 Fig. 4 Layout of the borehole field and the measurement points underground

641 Fig. 5 Illustration of the virtual simulation system developed using TRNSYS

642 Fig. 6 Structure of the DST model

643 Fig. 7 Schematic of the counter flow cooling tower model

644 Fig. 8 Validation results when the system operated without auxiliary cooling system

645 Fig. 9 Validation results when the system operated with auxiliary cooling system

646 Fig. 10 The relationship between PAHD and CTICR under different system operation scenarios

647 Fig. 11 The variation of ATRSHA and ATRSOU with the variation of CTICR

648 Fig. 12 The variation of ATRSHAS and ATRSOUS with the variation of CTICR in summer

649 Fig. 13 The variation of SEU and UEU with the variation of CTICR

650 Fig. 14 The variation of ACSEU with the variation of CTICR

651 Fig. 15 The variation of SEUS and UEUS with the variation of CTICR 


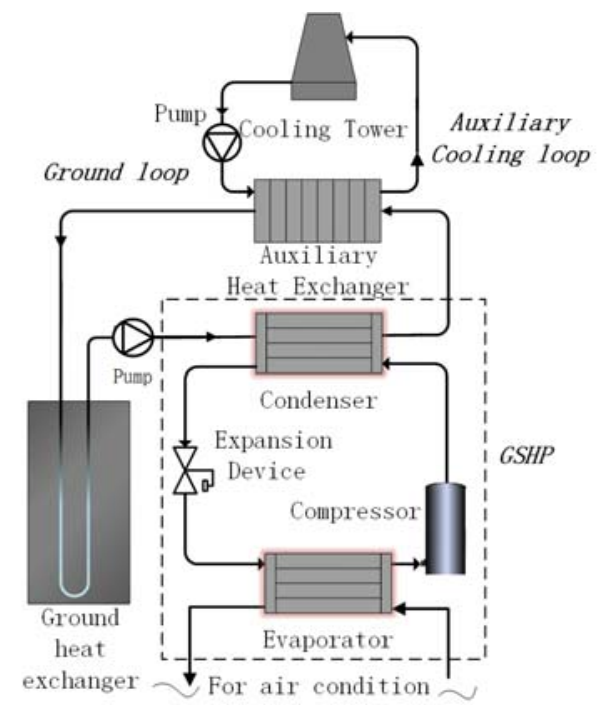

a) HGSHP with serial configuration

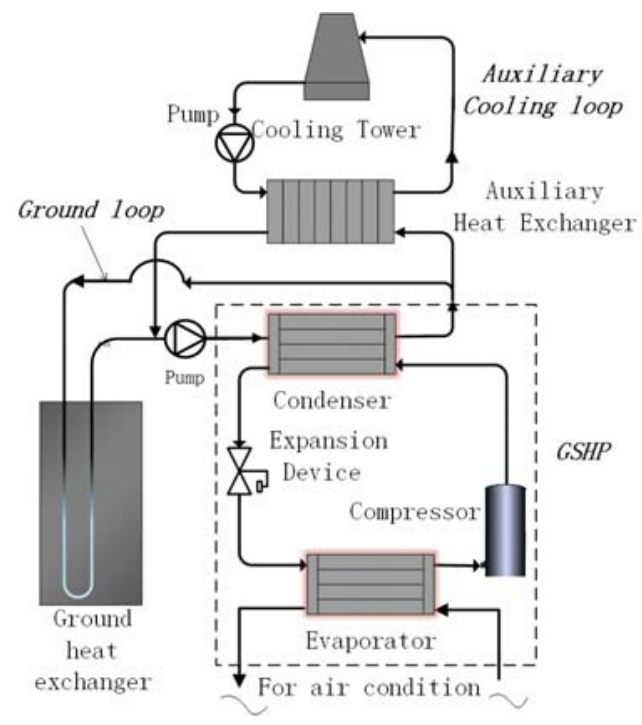

b) HGSHP with parallel configuration

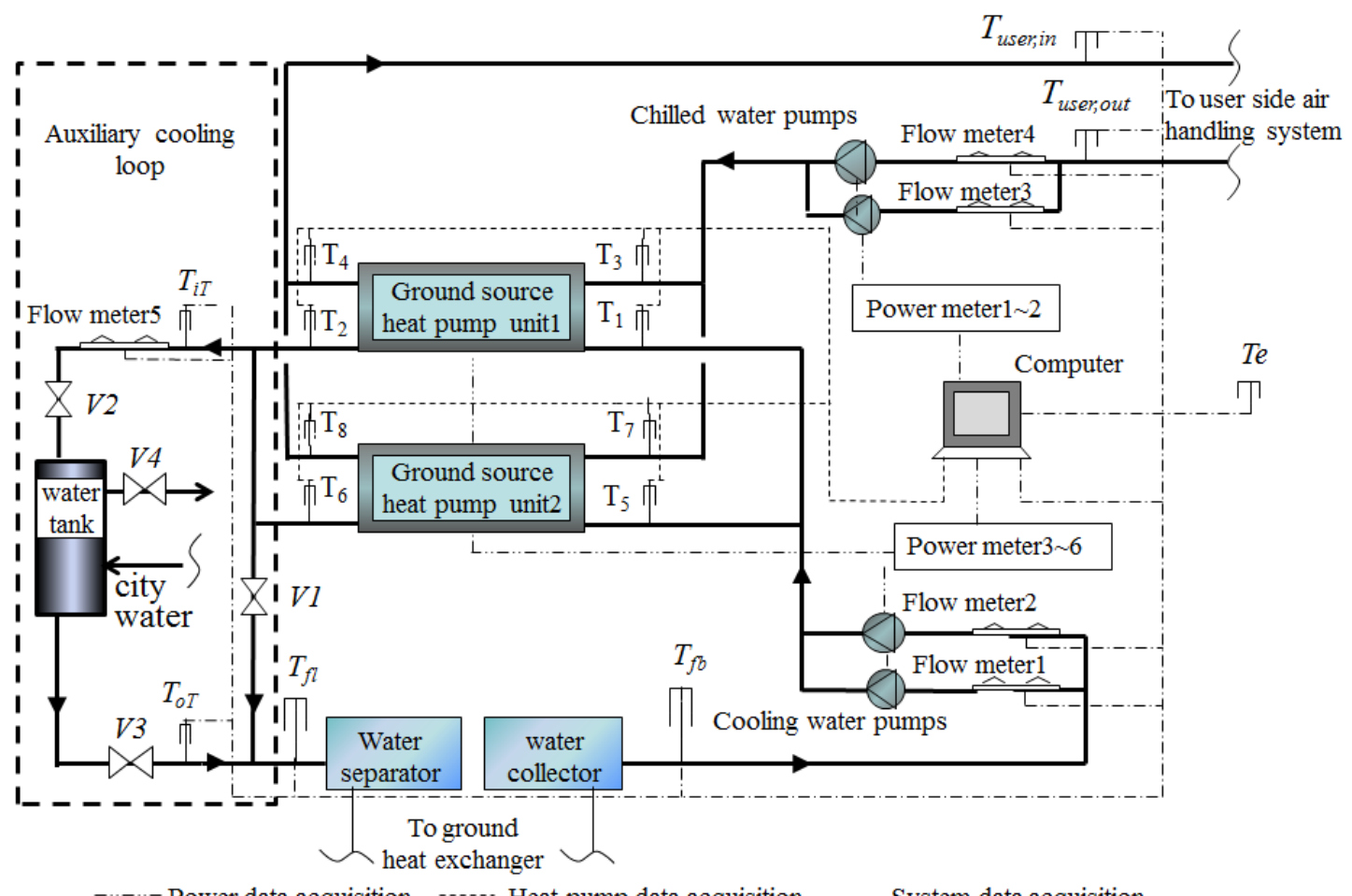

657 Fig. 2 Schematic of the experimental system and the measurement points above the ground. 


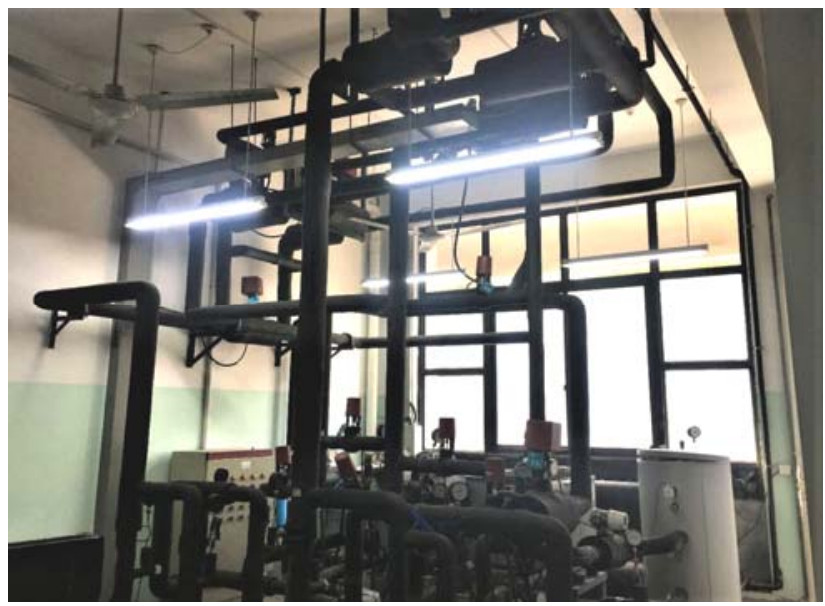

Fig. 3 Outlook of the experimental system.

661

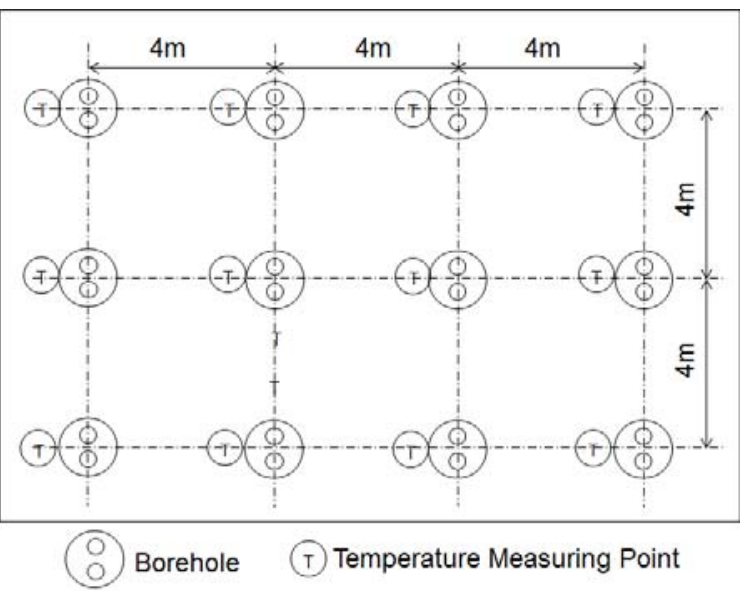

Fig. 4 Layout of the borehole field and the measurement points underground.

664

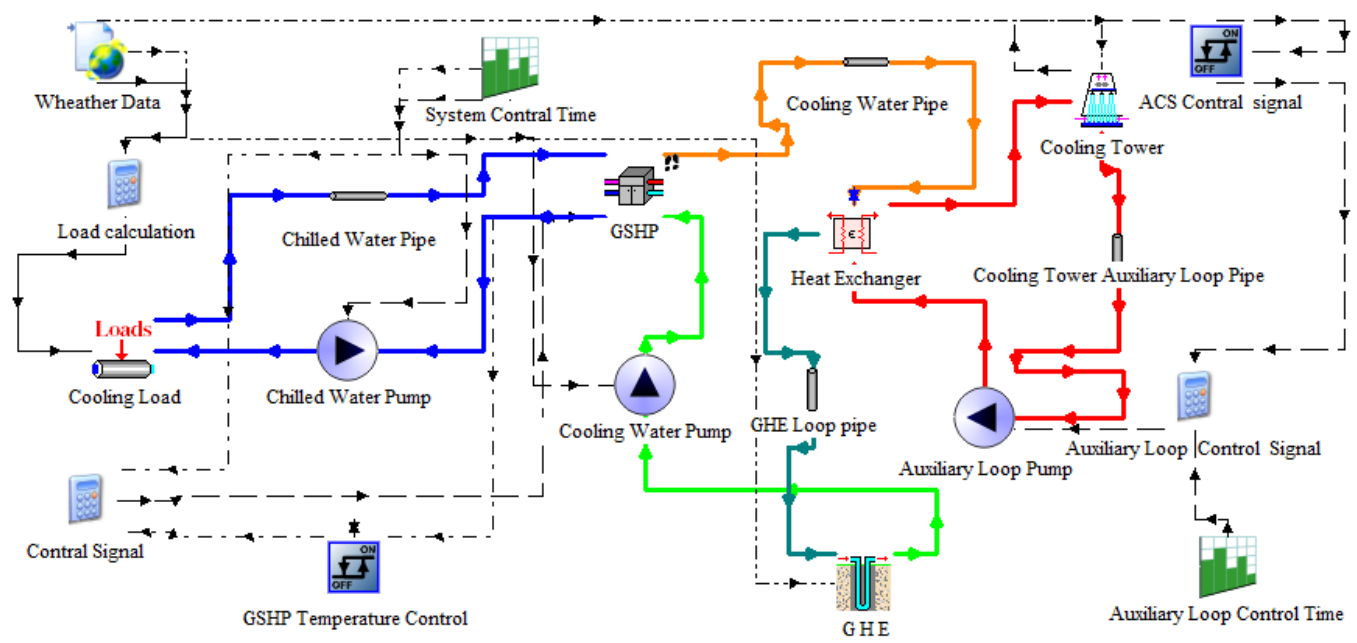

Fig. 5 Illustration of the virtual simulation system developed using TRNSYS. 


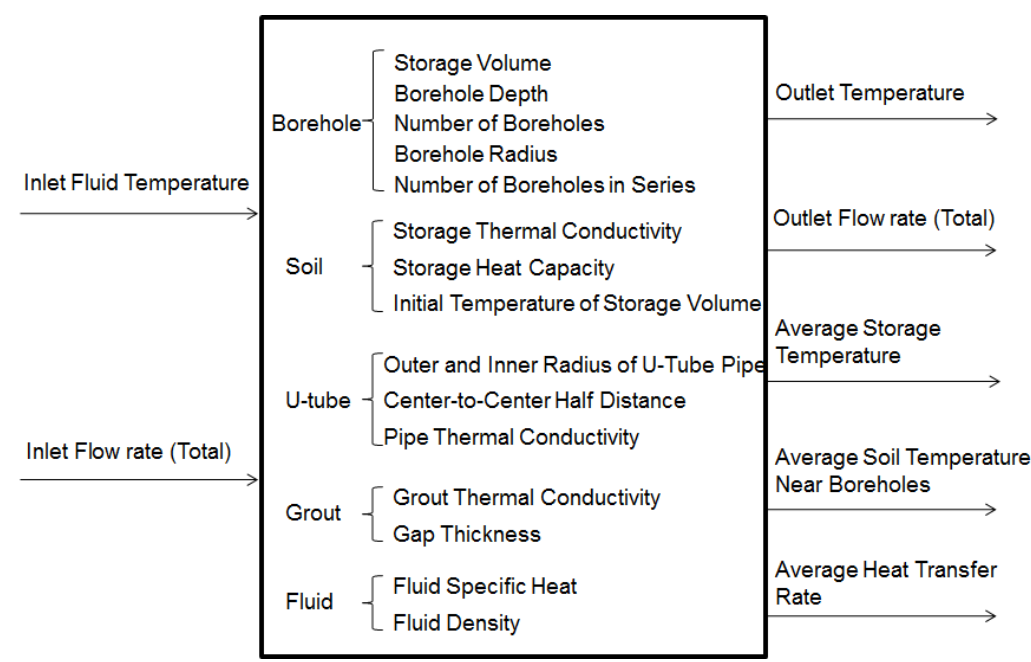

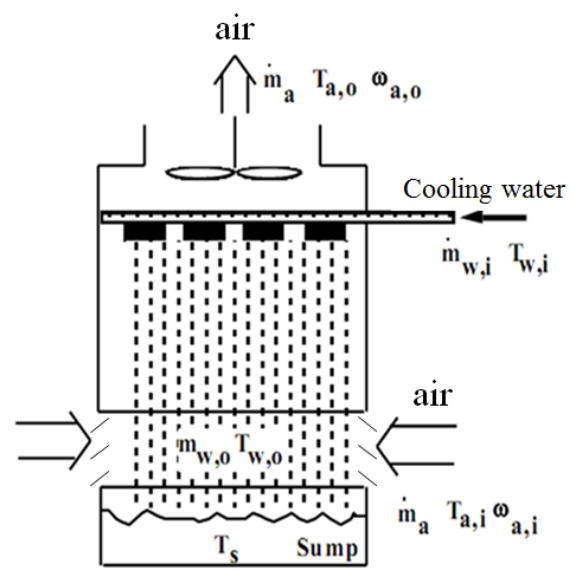

Fig. 7 Schematic of the counter flow cooling tower model. 


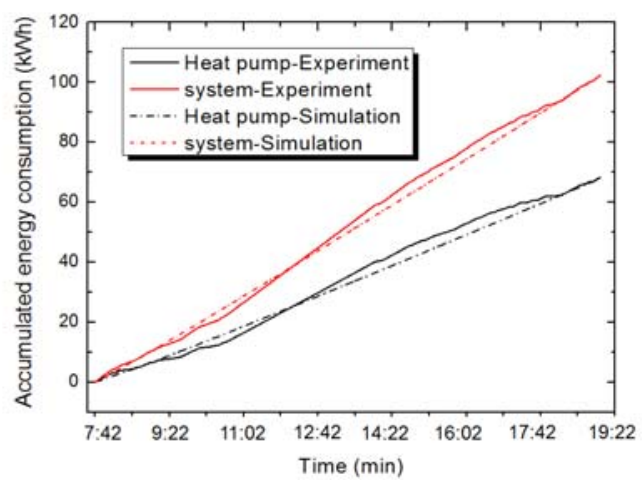

a) Accumulated power consumption

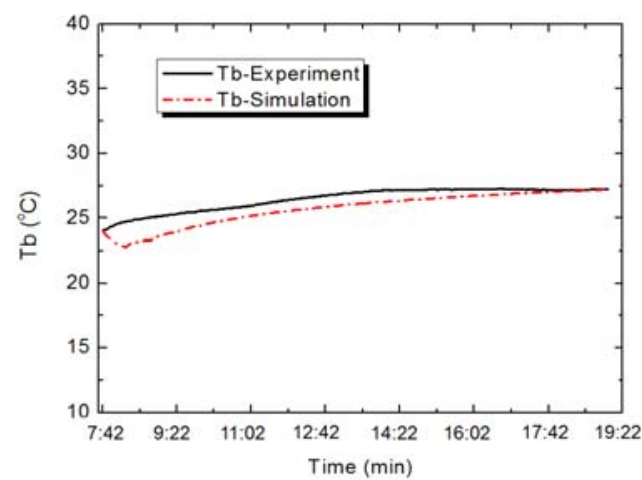

b) Borehole wall temperature

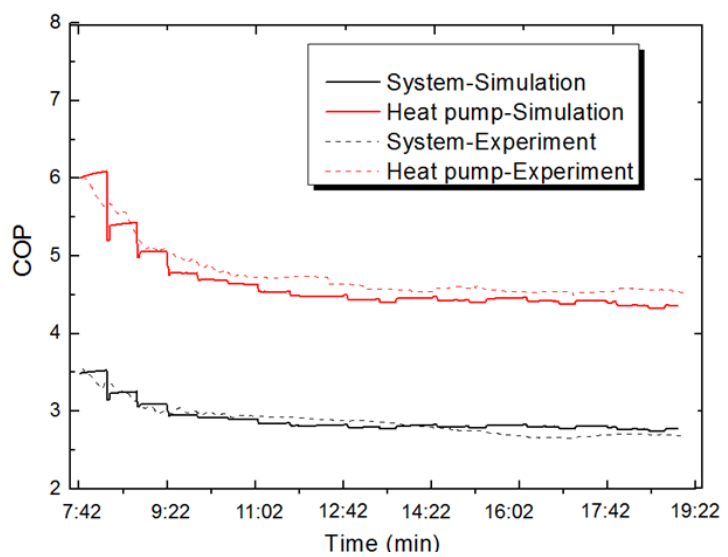

c) Instantaneous COP

Fig. 8 Validation results when the system operated without auxiliary cooling system.

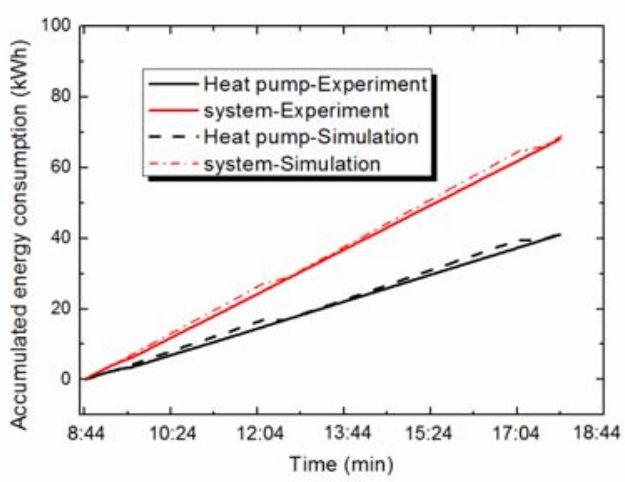

680

681

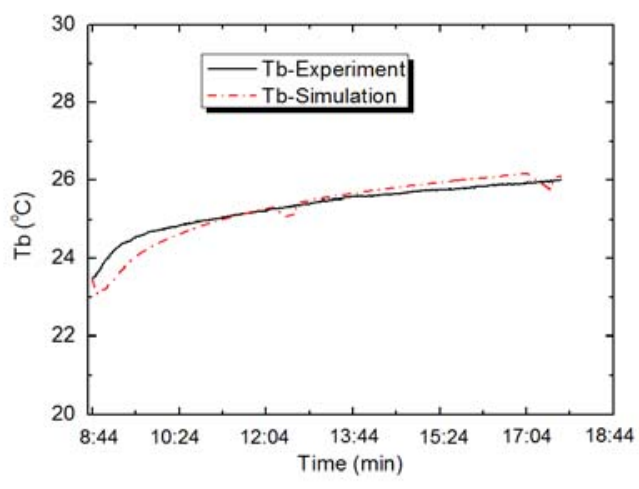

b) Borehole wall temperature 


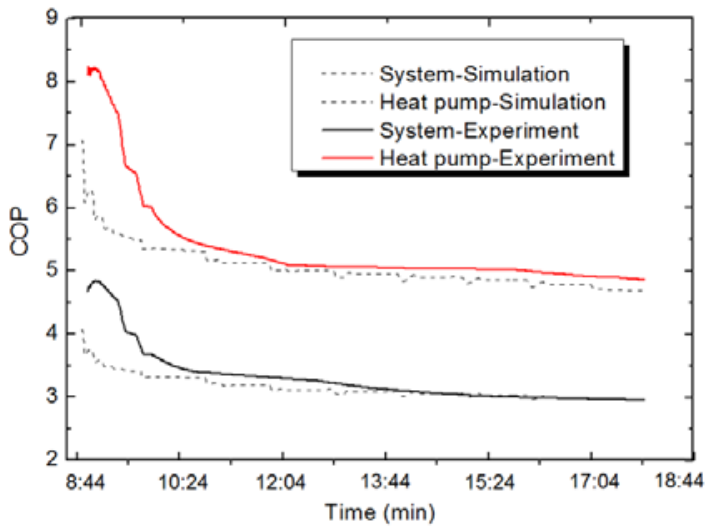

685

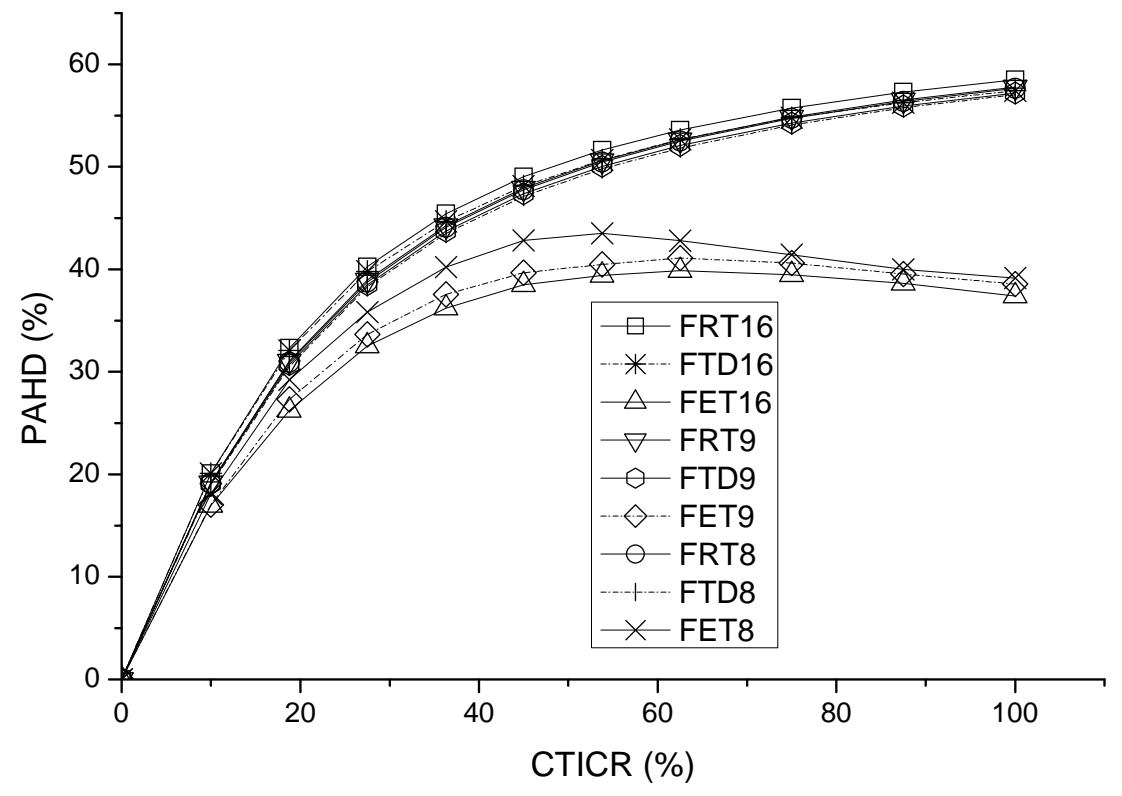

687 Fig. 10 The relationship between PAHD and CTICR under different system operation scenarios. 688 


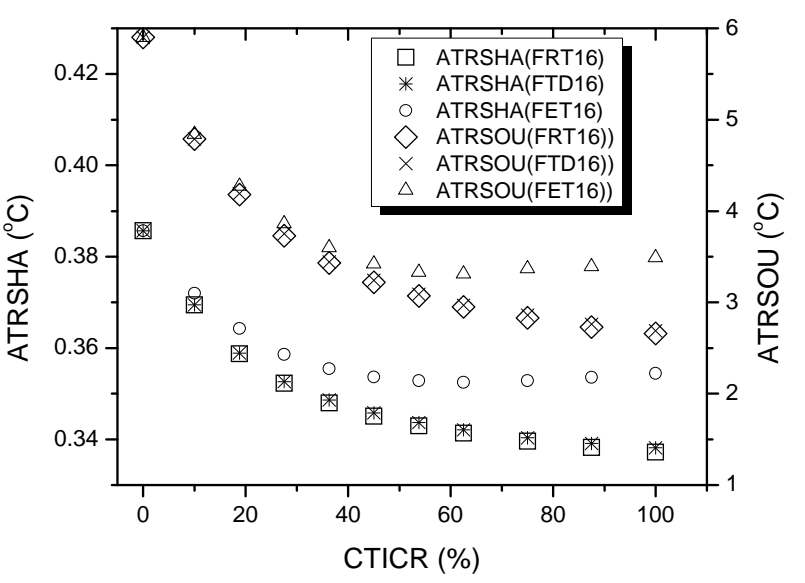

a) 16 hours operation

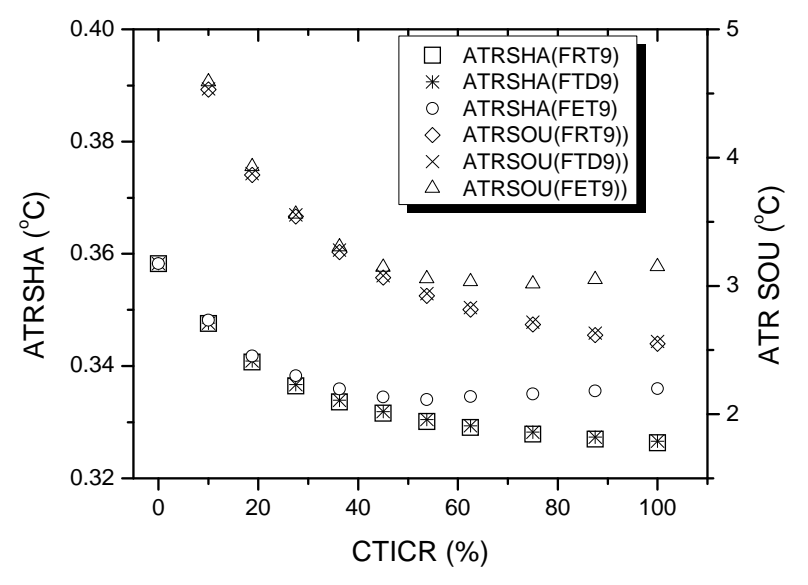

b) 9 hours operation
691

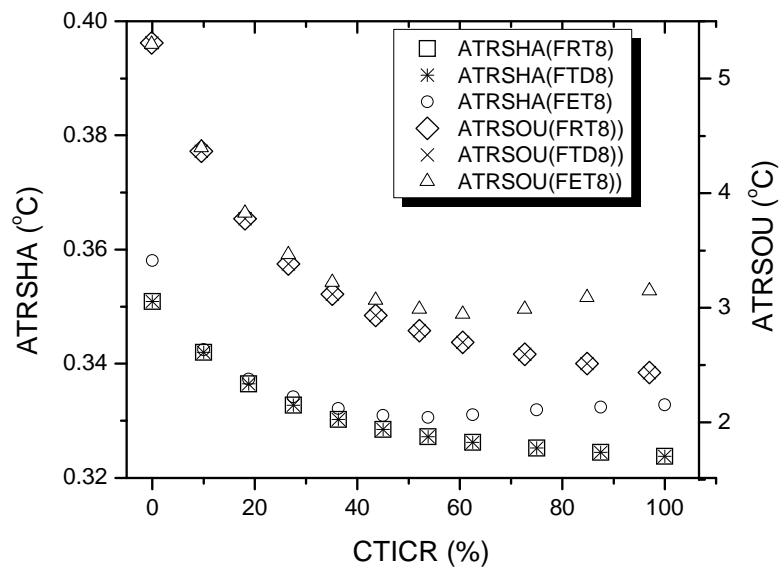

c) 8 hours operation

Fig. 11 The variation of ATRSHA and ATRSOU with the variation of CTICR.

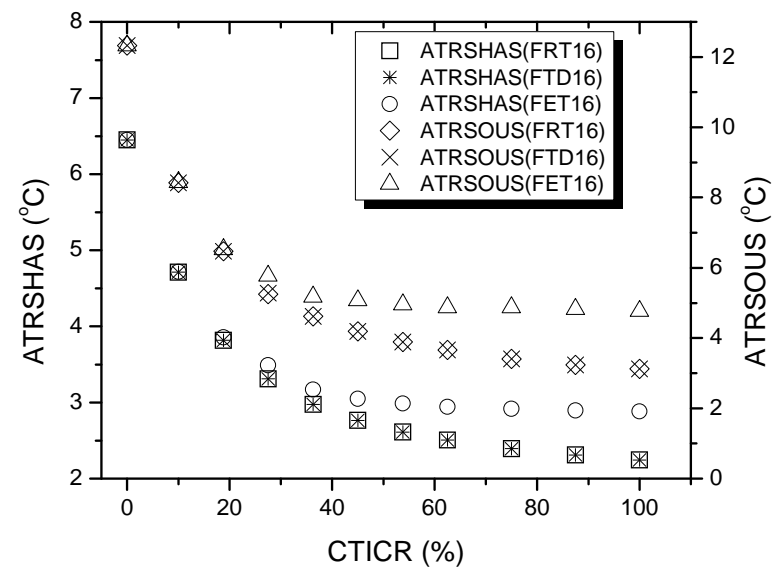

a) 16 hours operation

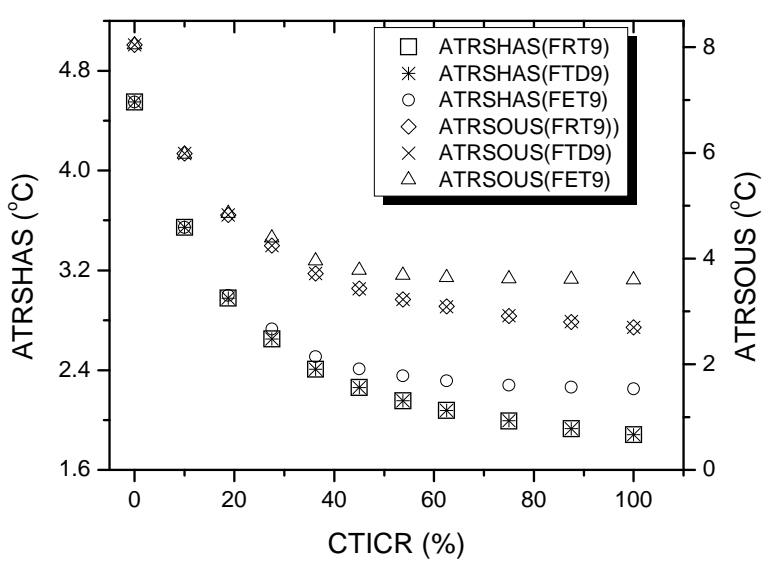

b) 9 hours operation 


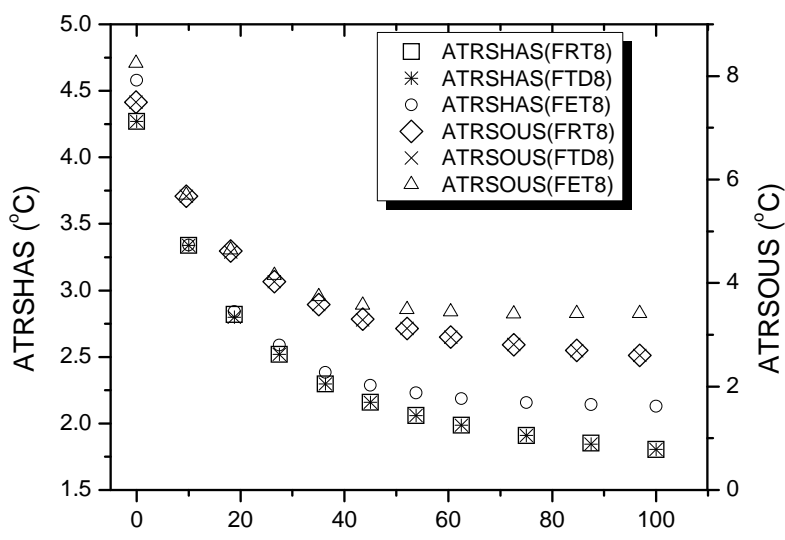

699 Fig. 12 The variation of ATRSHAS and ATRSOUS with the variation of CTICR in summer.

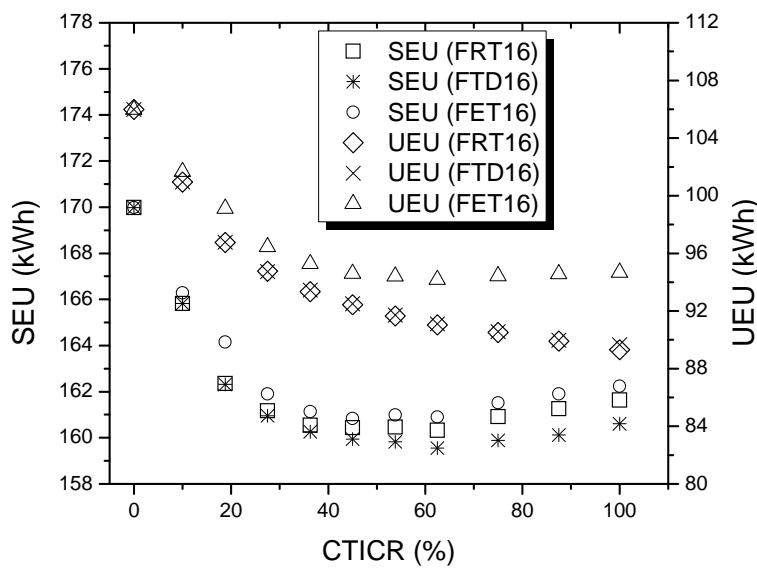

a)16 hours operation

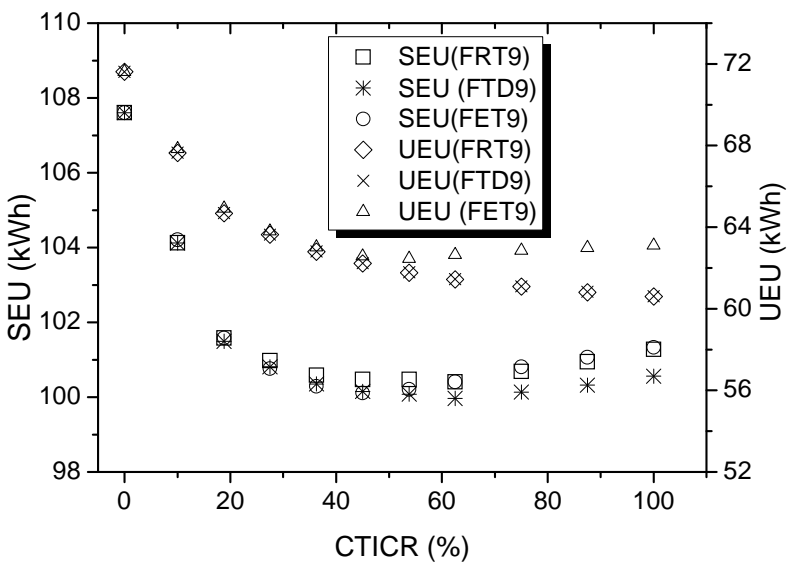

b) 9 hours operation

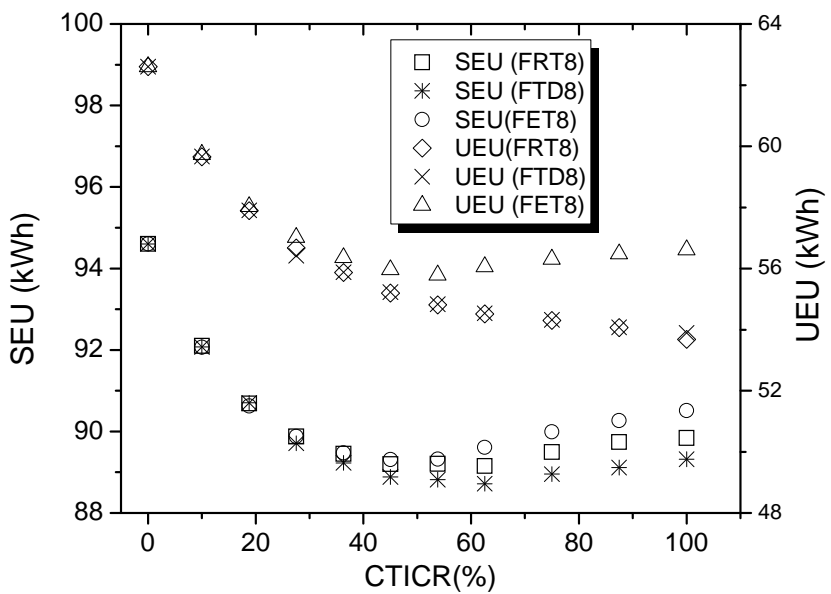

c) 8 hours operation 
707

708

709

710

711

712

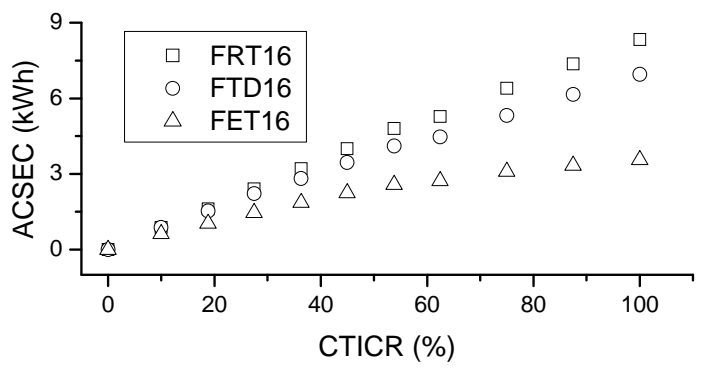

a) 16 hours operation

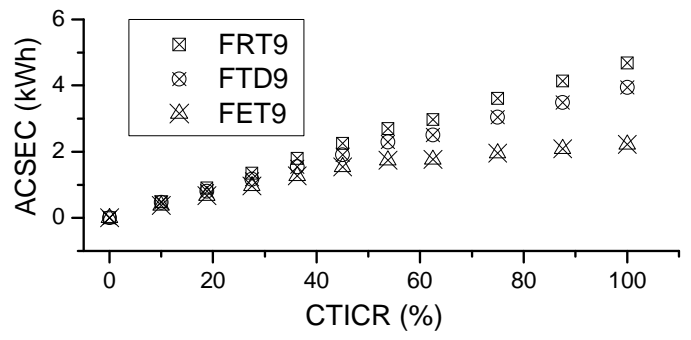

b) 9 hours operation

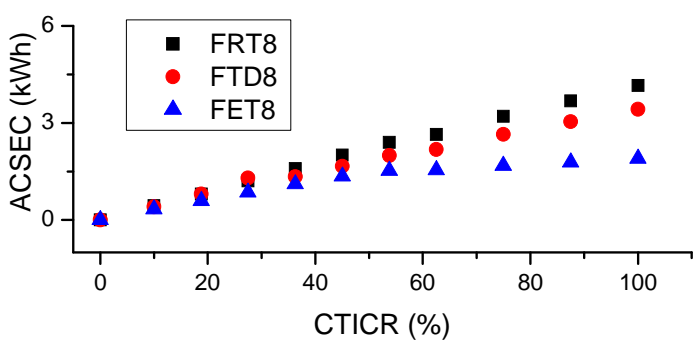

c) 8hours operation

Fig. 14 The variation of ACSEU with the variation of CTICR.

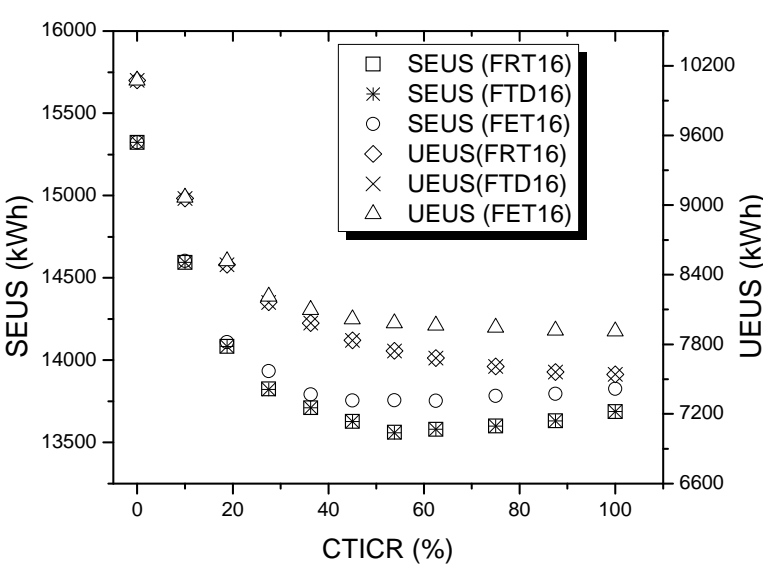

714 a) 16 hours operation

b) 9 hours operation 


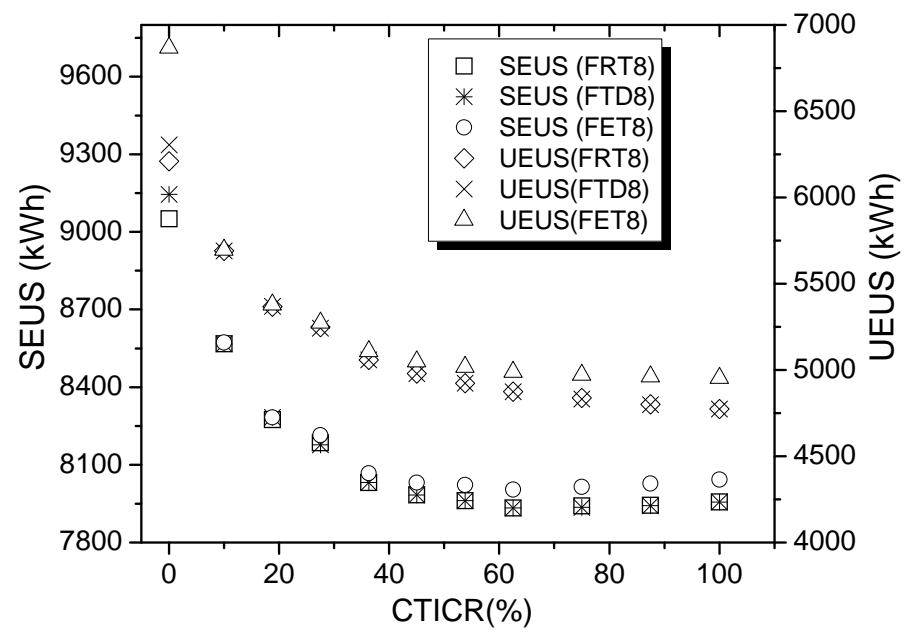

c) 8hours operation

Fig. 15 The variation of SEUS and UEUS with the variation of CTICR. 